\title{
Molecular Detection of Qol Resistance in Colletotrichum gloeosporioides Causing Strawberry Anthracnose Based on Loop-Mediated Isothermal Amplification Assay
}

\author{
J. Y. Wu, X. R. Hu, and C. Q. Zhang ${ }^{\dagger}$ \\ College of Agriculture and Food Science, Zhejiang A\&F University, Lin'an, Zhejiang, 311300, P.R. China
}

\begin{abstract}
Anthracnose is one of the most common diseases in strawberry plants. Colletotrichum gloeosporioides is the major cause of anthracnose in China, including Zhejiang Province. Early, specific, reliable, and timesaving detection is urgently needed to prevent the further spread of C. gloeosporioides, guiding farmers to utilize chemicals to control anthracnose. In this study, we showed that the high resistance to pyraclostrobin, caused by a point mutation at codon $143(\mathrm{GGT} \rightarrow \mathrm{GCT})$ in the cytochrome $b$ gene of $C$. gloeosporioides was prevalent in the strawberry growing regions, and we developed a loop-mediated isothermal amplification (LAMP) assay as a detection method. Primer sets S0 and S4 could be used to specifically detect $C$. gloeosporioides isolates and the G143A mutations, respectively. A detection limit of $10^{-2} \mathrm{ng}(10 \mathrm{pg})$, which is at least 10 -fold more sensitive than conventional polymerase chain

reaction, was achieved by the LAMP assay. Here, we utilized lateralflow devices (LFDs), nitrocellulose membranes that can absorb nucleic acids, to acquire the total genomic DNA of strawberry plants within $2 \mathrm{~min}$. The LFD membranes were used as DNA templates for the LAMP assays to accurately detect strawberry plants infected with C. gloeosporioides. This diagnostic method for strawberry anthracnose was accomplished within $1 \mathrm{~h}$, including the sample preparation and LAMP assays. Collectively, we developed a sensitive and practical method for monitoring $C$. gloeosporioides and its quinone outside inhibitor-resistant mutants. The LAMP assay for detection of $C$. gloeosporioides in strawberry plants has great potential for rapid strawberry anthracnose surveillance and will provide farmers with advice on preventing $C$ gloeosporioides at the early stages of strawberry development.
\end{abstract}

The genus Colletotrichum is primarily described as causing anthracnose diseases with sunken necrotic lesions on the fruits, stems, and leaves of extensive hosts, including woody and herbaceous plants, in tropical and subtropical regions (Damm et al. 2012b; Sutton et al. 1992). This genus is ranked eighth among the top 10 fungal plant pathogens worldwide based on scientific/economic significance (Dean et al. 2012). Anthracnose diseases mainly occur at preharvest and postharvest stages (Weir et al. 2012). The production, marketing, and export of tropical fruits and cereal crops, such as strawberry, mango, citrus, avocado, and banana, as well as maize and sorghum (Cannon et al. 2008, 2012; Giblin et al. 2010; Sreenivasaprasad and Talhinhas 2005), are particularly affected.

Strawberry (Fragaria $\times$ ananassa) is an important global small fruit crop and originated 250 years ago. Currently, China is the largest strawberry producer in the world (Zhao et al. 2012). Statistics show that the strawberry yield reached up to 4 million metric tons, creating a total output value of more than RMB 60 billion. Anthracnose caused by Colletotrichum spp. is a serious fungal disease in strawberry. Colletotrichum gloeosporioides and C. fragariae have been reported as the causal agents of strawberry anthracnose (Weir et al. 2012). However, a recent study indicated that C. gloeosporioides, which is actually a species complex, is the most prevalent agent of strawberry anthracnose in China, whereas the $C$. acutatum species complex causes anthracnose to a lesser extent (Damm et al. 2012a; Han et al. 2015; Xie et al. 2010). C. gloeosporioides threatens

${ }^{\dagger}$ Corresponding author: C. Q. Zhang; cqzhang@zafu.edu.cn

Funding: This study was supported by National Natural Science Foundation of China (no. 31801779), Science Technology Department of Zhejiang Province (no. 2045210317), and Education Department of Zhejiang Province (no. 2055210044).

The author(s) declare no conflict of interest.

Accepted for publication 19 January 2019.

@ 2019 The American Phytopathological Society the health of the strawberry during the entire plant growth cycle, especially at the seedling and transplanting stages. Anthracnose decreased the strawberry yield by $80 \%$ under suitable environmental conditions (Denoyes and Baudry 1995). At the nursery stage, pathogenic fungi can infect stolons, leading to latent infection, which results in the wilting and death of unrooted daughter plants after transplanting (Freeman and Katan 1997).

Fungicides with different modes of action, such as benzimidazole fungicides, demethylation inhibitors, or quinine outside inhibitors (QoIs), are used to control strawberry anthracnose. However, the efficacy of fungicides was remarkably reduced because of the occurrence of resistance. QoI fungicides, including azoxystrobin and pyraclostrobin, have commonly been introduced for the control of anthracnose in agriculture (Turechek et al. 2006; Wang et al. 2014). However, with the widespread use of QoIs, a significant increase in resistance to QoIs has occurred for a number of plant pathogenic fungi (Fernández-Ortuño et al. 2006; Fraaije et al. 2005; Genet et al. 2006; Köller et al. 2004; Siah et al. 2014; Torriani et al. 2008), and strains highly resistant to QoIs have been reported for different Colletotrichum species, including C. cereale (Wong et al. 2007; Young et al. 2010), C. gloeosporioides (Ishii et al. 2007), and C. graminicola (Avila-Adame et al. 2003). The resistance mechanism is based on a single point mutation in the mitochondrial cytochrome b (cyt b) gene, and the high resistance of Colletotrichum species to QoI fungicide was prompted by the glycine to alanine substitution at amino acid 143 (G143A) (Avila-Adame et al. 2003; Forcelini et al. 2018). In some plant pathogens, a change from phenylalanine to leucine at position 129 (F129L) or a change from glycine to arginine (G137R) also leads to lower resistance to QoIs (Dolores et al. 2010; Valeria et al. 2010). Currently, with the fungicide resistance of $C$. gloeosporioides and consumer demand for reducing the use of fungicides, there is a need for environmentally friendly and sustainable control measures that require the smarter use of fungicides to delay or manage resistance in pathogens.

C. gloeosporioides generally exists in healthy plant tissue because of its characteristics of latent infection. It is important to use fungicides in a smart manner during the early stages of development. To achieve this aim, we need to develop a rapid diagnostic method for 
detecting $C$. gloeosporioides infection of strawberry seedlings, including its pathogen resistance. Determining the plant pathogen and its resistance by traditional methods, which include fungal isolation and fungicide efficacy testing, is time consuming, and polymerase chain reaction (PCR) assays require expensive equipment. Loop-mediated isothermal amplification (LAMP) (Notomi et al. 2000 ) is a relatively new and rapid nucleic acid amplification technique that does not require a precision thermal cycler, thus making this method appropriate for use in the field compared with PCRbased detection assays. The LAMP assay has been used previously to detect several plant-pathogenic fungi and their resistance to fungicides (Duan et al. 2014; Hu et al. 2017). Traditional LAMP assays involve a complex genomic DNA extraction step, which limits the application of LAMP in practice. In a previous study, we generated a LAMP assay for the direct detection of Botrytis cinerea in strawberry samples (Hu et al. 2017).

In Zhejiang Province, China, the strawberry industry is one of the important fruit industries. Pyraclostrobin was registered for use against strawberry anthracnose. Based on the serious QoI resistance of $C$. gloeosporioides in the field, the current study was conducted to (i) monitor the evolution of resistance to pyraclostrobin of C. gloeosporioides in strawberry growing regions and investigate the molecular mechanism of pyraclostrobin resistance of $C$. gloeosporioides, (ii) establish a LAMP assay to detect pyraclostrobin resistance in populations of $C$. gloeosporioides, and (iii) apply the LAMP assay to detect $C$. gloeosporioides in strawberry plants.

\section{Materials and Methods}

Fungicide, reagents, and isolates. Technical-grade pyraclostrobin fungicide (99\% active ingredient) was dissolved in acetone at $10^{6} \mu \mathrm{g} / \mathrm{ml}$ and maintained as a stock solution for use in the in vitro assays in the present study.

The LAMP assay system contained the following reagents: Bst DNA Polymerase Large Fragment, 10× ThermoPol (Vazyme, Nanjing, China), betine, hydroxynaphthol blue (HNB) (Sigma, China), $\mathrm{MgCl}_{2}$, and double-distilled water $\left(\mathrm{ddH}_{2} \mathrm{O}\right)$ (Sangon Biotech, Shanghai, China).

The isolate ZJF-4 is highly resistant to pyraclostrobin with a point mutation at codon 143 (GGT $\rightarrow \mathrm{GCT})$ in the $c y t b$ gene. ZJC15-3 is a sensitive strain. Evidence of the sensitivity of these strains has been preconfirmed by minimum inhibitory concentration (MIC) testing and sequencing.

Single-conidial isolates of fungal isolates. A set of 93 singleconidial isolates of $C$. gloeosporioides were sampled from distinct strawberry greenhouses in four different geographical regions in Zhejiang Province, including Jiande, Zhuji, Ningbo, and Wenzhou

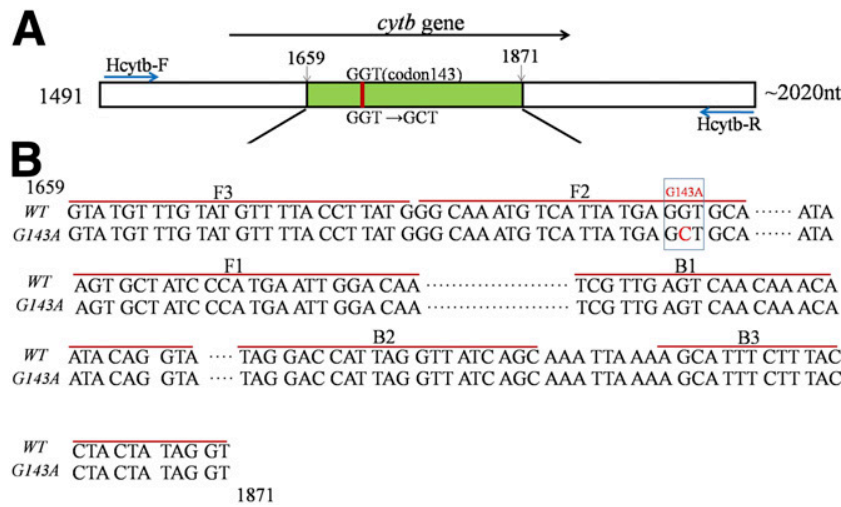

Fig. 1. Mapping of G143A loop-mediated isothermal amplification (LAMP) primers in the cytochrome $b$ (cyt $b$ ) gene of Colletotrichum gloeosporioides. A, Schematic representation of the site of the cyt $b$ gene fragment containing codon 143 and the G143A LAMP assay. The shaded box depicts the cyt $b$ gene fragment for designing LAMP primers. B, LAMP primers used to detect the G143A mutant genotype. The point mutation in the box leads to high resistance to quinine outside inhibitors. cities, in 2016. Juncture areas between sick and healthy tissues were cut from infected tissues to isolate plant pathogenic fungi, followed by surface disinfection based on the standard procedures (Duan et al. 2016). All samples were surface sterilized by using $1 \%$ sodium hypochlorite for $1 \mathrm{~min}$ and $70 \%$ ethanol for $1 \mathrm{~min}$, followed by washing three times with sterile distilled water. Six fragments of each sample were cut and placed on Petri dishes containing potato dextrose agar (PDA) supplemented with $50 \mu \mathrm{g} / \mathrm{ml}$ of streptomycin sulfate (Sangon Biotech). All plates were incubated at $25^{\circ} \mathrm{C}$ for 4 days. Fungi showing features characteristic of Colletotrichum were isolated on fresh PDA plates and incubated at $25^{\circ} \mathrm{C}$ for 7 days to observe conidia formation. The conidia were spread on water agar, and a single conidium was subcultured on PDA to obtain a monoconidial culture. The isolate was identified based on conidial morphology and growth rate in culture relative to reference cultures of C. gloeosporioides (Gunnell and Gubler 1992). The isolates were maintained on PDA slants at $4^{\circ} \mathrm{C}$

Detection of fungicide resistance in vitro. The inhibition of mycelial growth was measured by MIC testing to assess the resistance of C. gloeosporioides to pyraclostrobin. The solid PDA plates were amended with pyraclostrobin at $0,5,20$, and $100 \mu \mathrm{g} / \mathrm{ml}$ (final concentrations in $200 \mu \mathrm{l}$ of medium), as previously described (Zhang et al. 2010). After incubation for 2 to 3 days at $25^{\circ} \mathrm{C}$ in darkness, the resistance level of each $C$. gloeosporioides isolate was estimated according to strain growth on PDA plates containing 5, 20, or $100 \mu \mathrm{g} / \mathrm{ml}$ of pyraclostrobin. The bioassay was replicated twice, and similar results were obtained with both replications for each isolate.

Isolation of the $\boldsymbol{c y t} \boldsymbol{t} \boldsymbol{b}$ gene fragments of $\boldsymbol{C}$. gloeosporioides. Ten C. gloeosporioides isolates were randomly selected for different phenotypes of pyraclostrobin sensitivity. Five isolates (NBG-8, WZ1-1, WZ7-4, HZJ-1, and HJD-16) were resistant to pyraclostrobin, and the other five isolates (XSXS-3, XSXS-4, NBG-2, HZJ-2, and HJD-46) were sensitive. To extract DNA, the mycelia of each isolate were harvested from each strain on PDA after 5 days. Total DNA was extracted by using a fungal genomic DNA kit (Sangon Biotech). Then, the DNA concentration was measured by spectrophotometry and diluted with distilled water. The $c y t b$ gene fragment containing codon 143 was amplified by the PCR primer pair Hcytb-F (TAATCGCTACAGACTGGGTCAC) and Hcytb-R (CCTTTTGG TGTTTTACTTATTTG), designed according to the known complete sequence of the cyt $b$ gene in $C$. gloeosporioides (GenBank no. KX885104.1). The PCR was conducted in a total volume of $50 \mu \mathrm{l}$ containing $2 \times$ TransTaq HiFi SuperMixII $(25 \mu l$, TransGen Biotech, Beijing, China), template DNA $(2 \mu \mathrm{l})$, and $10 \mu \mathrm{M}$ Hcytb-F and Hcytb-R ( $1 \mu$ l each primer). PCR was conducted with denaturation at $94^{\circ} \mathrm{C}$ for $4 \mathrm{~min}$, followed by 35 cycles of $94^{\circ} \mathrm{C}$ for $30 \mathrm{~s}, 55^{\circ} \mathrm{C}$ for $30 \mathrm{~s}$, and $72^{\circ} \mathrm{C}$ for $30 \mathrm{~s}$, and further extension at $72^{\circ} \mathrm{C}$ for $10 \mathrm{~min}$. Subsequently, $1 \%$ agarose gel electrophoresis was performed to separate the PCR products, and the expected size bands were excised and purified by using the SanPrep Column PCR Product Purification Kit (Sangon Biotech). All purified PCR products were sequenced by Sangon Biotech.

LAMP primer design and optimization for detection of C. gloeosporioides G143A mutations. In the LAMP assay for the detection of $C$. gloeosporioides, we designed a set of four primers (S0), comprising two outer primers and two inner primers, based on the conserved $\beta$-tubulin sequence of $C$. gloeosporioides.

The LAMP assay was also used to detect $C$. gloeosporioides G143A mutation, which is responsible for high resistance to QoIs. Six sets of LAMP primers were designed and mismatched on the basis of a point mutation at codon $143(\mathrm{GGT} \rightarrow \mathrm{GCT})$ in the $c y t b$ gene by using Primer explorer V5 software (http://primerexplorer.jp/e/), as previously described (Hu et al. 2017). The LAMP primer sequences are shown in Figure 1 and Table 1, and the components of the assay system used in the present study were as follows. Each LAMP reaction mixture was set up to include the supplied buffer, $4 \mathrm{mM} \mathrm{Mg}^{2+}$, $1 \mathrm{mM}$ dNTP, $1.6 \mu \mathrm{M}$ forward inner primer (FIP1, FIP2, FIP3, FIP4, FIP5, and FIP6)/backward inner primer (BIP), $0.3 \mu \mathrm{M}$ F3/B3 primers, $0.6 \mathrm{M}$ betine, $150 \mu \mathrm{M}$ HNB, $0.16 \mathrm{U} / \mu 1$ Bst DNA Polymerase 
Large Fragment, and $100 \mathrm{ng} / \mu \mathrm{l}$ of sample DNA template, which were adjusted as previously described (Hu et al. 2017). G143A mutant ZJF-4 was used as a positive control template, whereas ZJC15-3, a sensitive strain, and $\mathrm{ddH}_{2} \mathrm{O}$ were used as the negative controls.

The LAMP reactions were carried out at $65^{\circ} \mathrm{C}$ for $60 \mathrm{~min}$ and then placed at $80^{\circ} \mathrm{C}$ for $5 \mathrm{~min}$. If the color of the $\mathrm{HNB}$ in reaction tubes changed from violet to sky blue, then the reaction was considered positive, whereas a violet color indicated a negative reaction. Moreover, each product $(5 \mu \mathrm{l})$ was analyzed on standard $1 \%$ agarose gels and stained with ethidium bromide. Each treatment was repeated at least three times, and the experiment was performed three times.

Specificity analysis of the LAMP assay. The genomic DNA extracted from C. atramentarium, C. capsici, C. truncatum, B. cinerea, or C. gloeosporioides (ZJF-4, ZJC15-3, and XSXS-3) and $\mathrm{ddH}_{2} \mathrm{O}$ were used as DNA templates for the LAMP specificity test. The LAMP reaction conditions adopted the optimal parameters determined above. The LAMP assay was performed three times, and each sample had three replicates.

Determining the ideal reaction conditions for the LAMP assay. To determine the optimal temperature and time for LAMP, the reaction conditions were adjusted as previously described $(\mathrm{Hu}$ et al. 2017). A series of constant temperatures, including 58.0, 59.0, $60.0,61.0,62.0,63.0,64.0,65.0,66.0,67.0$, and $68.0^{\circ} \mathrm{C}$, were set to detect the optimal reaction temperature. Then, the LAMP reactions were performed for $15,30,40,50,60,70,80$, and $90 \mathrm{~min}$ at the optimal reaction temperature to define the shortest reaction time. The results were observed as describe above. The experiments were performed three times, and each sample had three replicates. The optimized parameters for the LAMP assay were used for the following detection of C. gloeosporioides.

Sensitivity comparison of LAMP and PCR. The DNA template for amplification was diluted with $\mathrm{dd}_{2} \mathrm{O}$. Decreasing amounts of DNA (10 to $\left.10 \times 10^{-7} \mathrm{ng} / \mu \mathrm{l}\right)$ were added to LAMP reaction or PCR. In the LAMP assay, the product was amplified with optimal LAMP primers and reaction components under optimal reaction conditions as described above. Conventional PCR was conducted by using the primers F3 and B3. Following amplification, the LAMP products were analyzed by gel electrophoresis and HNB visualization, and the PCR products were assessed by gel electrophoresis. The experiments were performed three times, and each sample had three replicates.

LAMP assay for detection of $C$. gloeosporioides in strawberry plants. Twenty strawberry plants, which were suspected of carrying strawberry anthracnose, were collected from the strawberry greenhouse in Jiande. It was unclear whether the strawberry plants were infected by $C$. gloeosporioides, because these plants lacked the typical anthracnose symptoms. Lateral-flow devices (LFDs) typically contain a nitrocellulose membrane, and both nucleic acids and proteins can be absorbed by the release pad of extraction LFDs. Genomic DNA from strawberry plants was extracted by using LFDs, as previously described (Tomlinson et al. 2010). For the LAMP assay, genomic DNA from shortened stem, stem, petiole, and leaf tissues (each sample $100 \mathrm{mg}$ ) was extracted by using LFDs. Additionally, the above plant tissues were cut off and used to isolate $C$. gloeosporioides. When LFDs were being tested in LAMP, $5 \times 1 \mathrm{~mm}$ of LFD membrane was used as the DNA template in a $25-\mu$ l LAMP reaction. The primer set S0 was used for diagnosing anthracnose in strawberry plants. The experiments were performed three times, and each sample had three replicates.

\section{Results}

Pyraclostrobin resistance of $C$. gloeosporioides was widely spread in strawberry populations in Zhejiang Province. Different levels of QoI resistance were detected in the tested populations (Zhang et al. 2010). In 93 single-conidial isolates of C. gloeosporioides, 66 isolates could grow on PDA plates amended with $100 \mu \mathrm{g} / \mathrm{ml}$ of pyraclostrobin, and the high resistance frequency was up to $71.0 \%$. The high resistance ratio of $C$. gloeosporioides collected from Wenzhou was $100 \%$, and those of $C$. gloeosporioides collected from Zhuji, Hangzhou, and Ningbo were 83.33, 50, and $78.26 \%$, respectively. These results showed that severe resistance of $C$. gloeosporioides to pyraclostrobin was widespread in the strawberry greenhouses in Zhejiang Province.

G143A mutation is responsible for the high resistance to QoI fungicides in $\boldsymbol{C}$. gloeosporioides. In the present study, a fragment of the cyt $b$ gene of $C$. gloeosporioides containing the positions known to affect the sensitivity to QoI fungicides was sequenced. The sequencing results showed that the target sequence of five sensitive strains (XSXS-3, XSXS-4, NBG-2, HZJ-2, and HJD-46) was $100 \%$ homologous to the sequence of $c y t b$ gene used for primer design. In addition, all resistant strains, NGB-8, WZ1-1, WZ7-4, HZJ1 , and HJD-16, had a point mutation at codon 143 (GGT $\rightarrow$ GCT) in the $c y t b$ gene, resulting in a glycine to alanine $(\mathrm{G} \rightarrow \mathrm{A})$ substitution. These results directly indicated that a change at amino acid 143 in the cyt $b$ induces QoI resistance in $C$. gloeosporioides, consistent with previous reports.

Screening LAMP primers for detecting $C$. gloeosporioides G143A mutations. Template DNA from a high-resistance isolate of $C$. gloeosporioides (ZJF-4) carrying the G143A mutation and a sensitive isolate (ZJC15-3) was used to assess six sets of mismatched LAMP primers based both on color changes in HNB (Fig. 2B) and separation on $1 \%$ agarose gels by electrophoresis (Fig. 2A). A positive result was signified by a change in the color of the HNB in the reaction mixture from violet to blue and the appearance of a product as a typical ladder-like band on gel electrophoresis. In contrast, a negative result was signified by the color of the HNB remaining violet and no amplified product shown on the gel. The results indicated that only the primer set $\mathrm{S} 4$ (F3/B3/FIP4/BIP) could specifically distinguish the G143A genotype of $C$. gloeosporioides from QoI-sensitive

Table 1. List of primers used for loop-mediated isothermal amplification assay in this study

\begin{tabular}{|c|c|c|c|c|}
\hline $\begin{array}{l}\text { Primer } \\
\text { name }\end{array}$ & $\begin{array}{l}\text { Primer } \\
\text { set }\end{array}$ & Type & Genome position & Sequence $\left(5^{\prime} \rightarrow 3^{\prime}\right)$ \\
\hline Hcytb-F & & Forward & cyt $b, 1,491-1,512$ & TAATCGCTACAGACTGGGTCAC \\
\hline Hcytb-R & & Backward & cyt $b, 1,998-2,020$ & CCTTTTGGTGTTTTACTTATTTG \\
\hline Tu-F3 & & Forward outer & $\beta$-tubulin, 399-417 & CTCGACAGCAATGGAGTGT \\
\hline Tu-R3 & & Backward outer & $\beta$-tubulin, 596-613 & TACTTGTTGCCGGAAGCC \\
\hline Tu-FIP & S0 & Forward inner & $\beta$-tubulin, 434-452, 474-493 & GGAGCTCAGAGGTGCCGTTG CTGGCCACATTGGTGGTTG \\
\hline Tu-BIP & & Backward inner & $\beta$-tubulin, 533-554, 577-594 & ACCTTATAGCCCCCAGAGTGCAGGGTAGGAGCGAAGGTCA \\
\hline F3 & & Forward outer & cyt $b, 1,659-1,683$ & GTATGTTTGTATGTTTTACCTTATG \\
\hline B3 & & Backward outer & cyt $b, 1,848-1,871$ & ACCTATAGTAGGTAAAGAAATGCT \\
\hline FIP1 & S1 & Forward inner & cyt $b, 1,725-1,749,1,684-1,703$ & GTCCAATTCATGGGATAGCACTTATGGCAAATGTCATTATGAGCC \\
\hline FIP2 & S2 & Forward inner & cyt $b, 1,725-1,749,1,684-1,703$ & GTCCAATTCATGGGATAGCACTTATGGCAAATGTCATTATGAGCĀ \\
\hline FIP3 & S3 & Forward inner & cyt $b, 1,725-1,749,1,684-1,703$ & GTCCAATTCATGGGATAGCACTTATGGCAAATGTCATTATGATCT \\
\hline FIP4 & S4 & Forward inner & cyt $b, 1,725-1,749,1,684-1,703$ & GTCCAATTCATGGGATAGCACTTATGGCAAATGTCATTATGAT̄CA \\
\hline FIP5 & S5 & Forward inner & cyt $b, 1,725-1,749,1,684-1,704$ & GTCCAATTCATGGGATAGCACTTATGGCAAATGTCATTATGAḠCT $\underline{C}$ \\
\hline FIP6 & S6 & Forward inner & cyt $b, 1,725-1,749,1,684-1,703$ & GTCCAATTCATGGGATAGCACTTATGGCAAATGTCATTATGAACT ${ }^{-}$ \\
\hline BIP & & Backward inner & cyt $b, 1,756-1,780,1,819-1,839$ & TCGTTGAGTCAACAAACAATACAGTGCTGATAACCTAATGGTC̄CTA \\
\hline
\end{tabular}


isolates, and therefore this primer set was used in subsequent tests in the present study.

Moreover, primer set S0, which failed to detect C. atramentarium, $C$. capsici, $C$. truncatum, and B. cinerea, could be used for diagnosing strawberry anthracnose caused by $C$. gloeosporioides (Fig. 3).

Optimization of temperature and time for the detection of C. gloeosporioides by LAMP. To determine the optimal reaction conditions for subsequent experiments, the LAMP reaction system was conducted under a range of temperatures or times. The specific primer S4 was used to determine the optimal running conditions for the LAMP reactions based on HNB visualization and gel electrophoresis analysis. The results showed that the LAMP amplification reaction could be performed at 58 to $65^{\circ} \mathrm{C}$ (Fig. 4). The color of the reaction mixture was more pronounced and the ladder-like bands on gel electrophoresis were intense at 62 and $63^{\circ} \mathrm{C}$ (Fig. 4). LAMP was performed at $62^{\circ} \mathrm{C}$ to optimize the shortest reaction time, and the results showed that suitable detection could be achieved at $62{ }^{\circ} \mathrm{C}$ for $50 \mathrm{~min}$ (Fig. 5). Thus, the optimum reaction condition for the detection of $C$. gloeosporioides G143A mutation by LAMP assay was $62^{\circ} \mathrm{C}$ for $50 \mathrm{~min}$.

The primer set S0 was suitable to detect $C$. gloeosporioides by using the same methods as above, and the optimum reaction condition for the LAMP assay was $65^{\circ} \mathrm{C}$ for $50 \mathrm{~min}$ (data not shown).

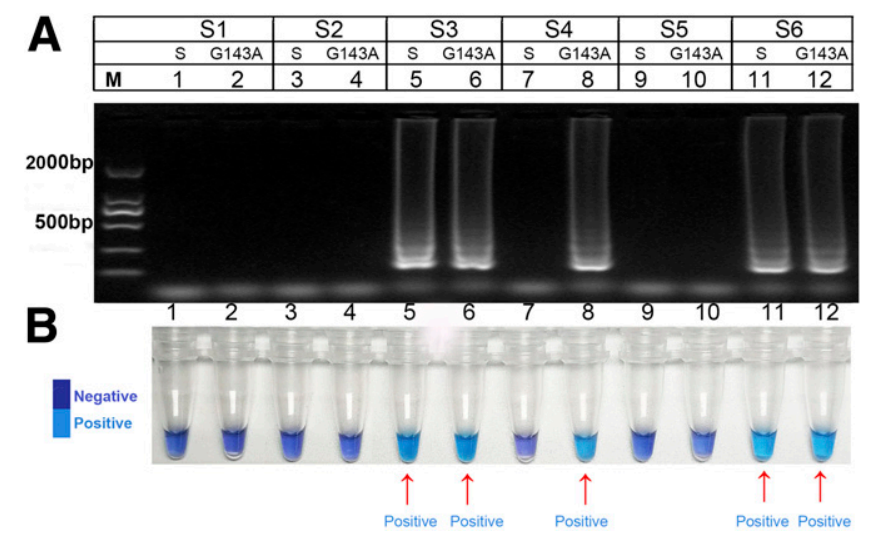

Fig. 2. Determining six sets ( $S 1$ to $S 6$ ) of loop-mediated isothermal amplification (LAMP) primers. Labels 1, 3, 5, 7, 9, and 11: the template DNA was extracted from pyraclostrobin sensitive strains (S). Labels $2,4,6,8,10$, and 12: the template DNA was extracted from the Colletotrichum gloeosporioides isolates with the G143A mutation. A, LAMP product detected by $1 \%$ agarose gel electrophoresis. Lane $\mathrm{M}$ represents the DL2000 DNA marker. B, Hydroxynaphthol blue-based visual changes in colors. The positive samples are indicated by arrows.

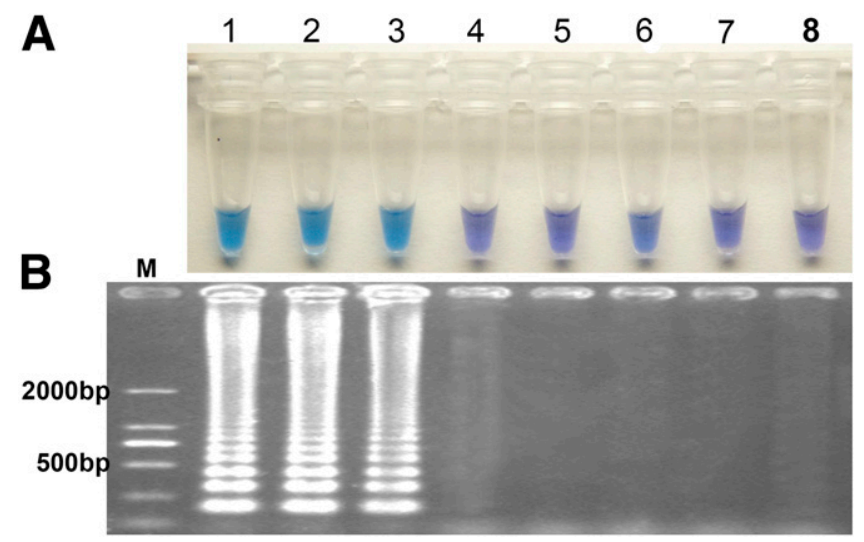

Fig. 3. Loop-mediated isothermal amplification (LAMP) detection of different Colletotrichum spp. Lanes 1 to 3 , three isolates of C. gloeosporioides, ZJF-4, ZJC15-3, and XSXS-3. Lanes 4 to 7, C. atramentarium, C. capsici, C. truncatum, and Botrytis cinerea. Lane 8, dd ${ }_{2} \mathrm{O}$. A, Hydroxynaphthol blue-based visual changes in colors. B, LAMP product detected by $1 \%$ agarose gel electrophoresis. Lane M represents the DL2000 DNA marker.
High accuracy of LAMP for the detection of $C$. gloeosporioides G143A mutants. As shown in Figure 6, under the optimized time and temperature, in the LAMP assay with primer set S4, the HNB appeared sky blue, indicating that the samples resistant to QoI fungicides contained a point mutation at amino acid $143(\mathrm{G} \rightarrow \mathrm{A})$. The color of the HNB in five tubes turned to sky blue, and the other five tubes remained violet (Fig. 6). According to the results of QoI fungicide resistance in $C$. gloeosporioides by the MIC method, the five discoloration isolates could grow on $100 \mu \mathrm{g} / \mathrm{ml}$ of pyraclostrobin (data not shown). Meanwhile the five isolates with a point mutation at codon 143(GGT $\rightarrow$ GCT) were also confirmed by sequencing, after genomic DNA was amplified by PCR using the primers Hcytb-F and Hcytb-R (data not shown).

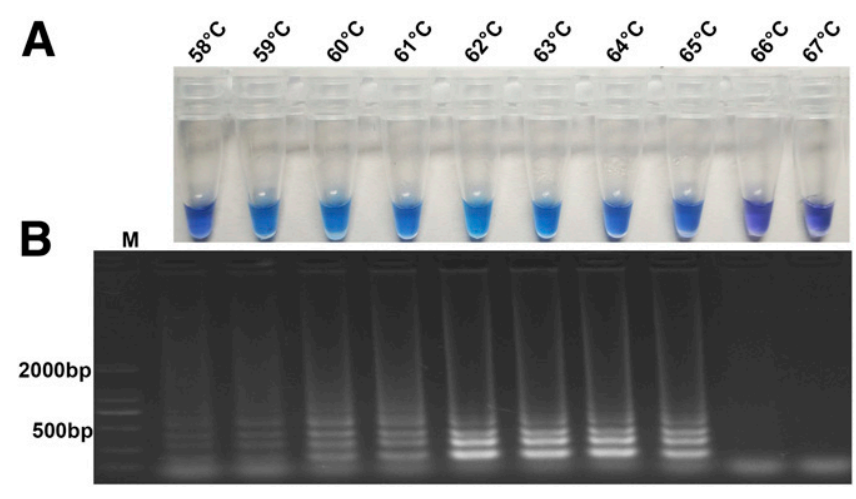

Fig. 4. Optimization of the reaction temperature for loop-mediated isothermal amplification (LAMP) for the detection of the G143A mutant genotype of Colletotrichum gloeosporioides. A, Hydroxynaphthol blue-based visual changes in colors. B, LAMP product detected by $1 \%$ agarose gel electrophoresis. Lane M represents the DL2000 DNA marker.

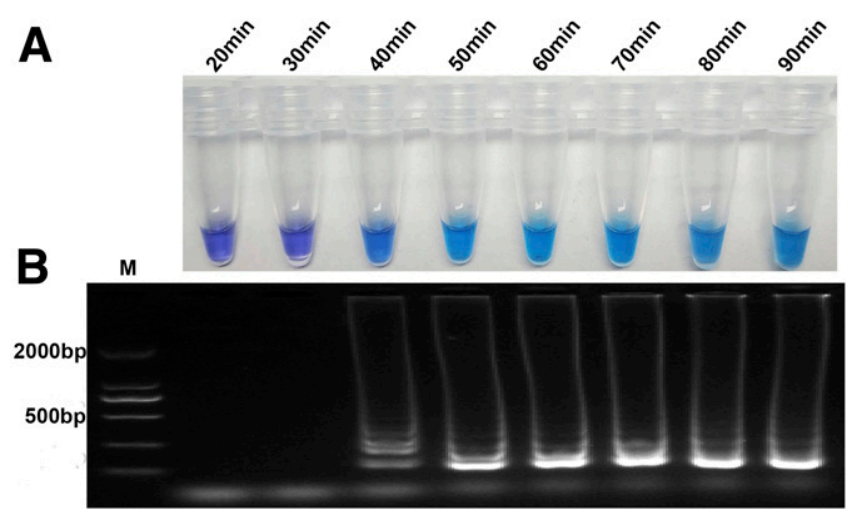

Fig. 5. Optimization of the reaction time for loop-mediated isothermal amplification (LAMP) for the detection of the G143A mutant genotype of Colletotrichum gloeosporioides. A, Hydroxynaphthol blue-based visual changes in colors. B, LAMP product detected by $1 \%$ agarose gel electrophoresis. Lane M represents the DL2000 DNA marker.

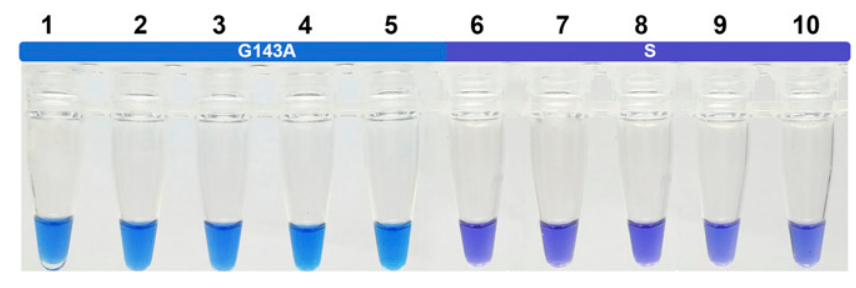

Fig. 6. Colletotrichum gloeosporioides $\mathrm{G} 143 \mathrm{~A}$ mutants from positive strawberry plants were detected by loop-mediated isothermal amplification (LAMP) assay. Hydroxynaphthol blue color changes in the LAMP reaction. Labels 1, 2, 3, 4, and 5: C. gloeosporioides isolates with the G143A mutation. Labels $6,7,8,9$, and 10: quinine outside inhibitor-sensitive (S) C. gloeosporioides isolates. 
LAMP is more sensitive than PCR. To characterize the sensitivity of LAMP, a 10-fold serial dilution of the genomic DNA template was used in the LAMP assay, and the results were compared with those obtained with conventional PCR. Gel electrophoresis and HNB-based visual changes in color both showed that LAMP successfully detected as little as $10 \times 10^{-3} \mathrm{ng}$ of DNA (Fig. 7A and B); however, the detection limit of PCR was $10 \times 10^{-2} \mathrm{ng}$ of DNA (Fig. 7C). Comparisons between the LAMP and conventional PCR demonstrated that LAMP sensitivity was at least 10 times higher than PCR.

Detection of $C$. gloeosporioides in strawberry plants within $1 \mathbf{h}$. Genomic DNA from all field plant samples was extracted by using LFD as described in the Materials and Methods. The LFD membranes were directly added to the LAMP mixture as DNA templates.

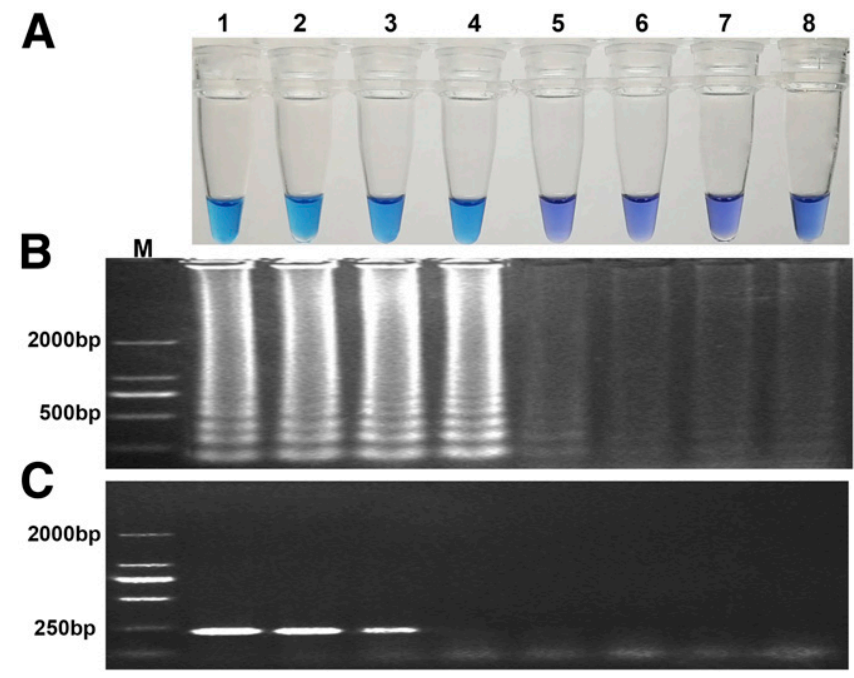

Fig. 7. Sensitivity of loop-mediated isothermal amplification (LAMP) for the detection of Colletotrichum gloeosporioides compared with conventional polymerase chain reaction (PCR). Lane M represents the DL2000 DNA marker. Serial dilutions of the DNA templates at $10,10 \times 10^{-1}, 10 \times 10^{-2}, 10 \times 10^{-3}, 10 \times 10^{-4}, 10 \times 10^{-5}$, $10 \times 10^{-6}$, and $10 \times 10^{-7} \mathrm{ng} / \mu$ l (lanes 1 to 8 , respectively) in LAMP or PCR reactions. A, Hydroxynaphthol blue-based visual changes in colors. B, LAMP product detected by $1 \%$ agarose gel electrophoresis. C, PCR product detected by $1 \%$ agarose gel electrophoresis. Lane M represents the DL2000 DNA marker.
DNA extraction and the LAMP assay were finished in $1 \mathrm{~h}$. Nineteen positive samples were detected from 20 strawberry plants by LAMP assay and tissue isolation. C. gloeosporioides was isolated by tissue isolation from the shortened stem, stalk, and petiole but not from the leaf (Table 2). These results were consistent with those obtained from the strawberry plant DNA LAMP with the primer set S0 (Table 2). Therefore, the detection of positive-sample ratios of strawberry plants by LAMP assay was consistent with detection by tissue separation.

\section{Discussion}

Anthracnose is one of the major diseases in strawberry plants, and its pathogenic fungi were registered as quarantine objects in many countries (de los Santos García de Paredes and Romero Munoz 2002). Anthracnose is caused by Colletotrichum spp., and fungicide application for the control of the occurrence of this disease is limited because of the spreading of Colletotrichum spp. and the susceptibility of strawberry plants to Colletotrichum spp. during all stages of development (Freeman et al. 1997). In the latent infection stage of anthracnose, the infected strawberry plant maintains a fit appearance, increasing the difficulty of disease diagnosis. To isolate these from "healthy" strawberry plants, the samples were treated with the herbicide paraquat, ethanol immersion, ultraviolet light, or freezing for inducing and detecting latent Colletotrichum spp., but all of these methods took five or more days to complete (Dhingra and Asmus 1983; Mertely and Legard 2004; Romero et al. 2018; Shirata 1993; Yamazaki et al. 1995). The PCR and immune-electron microscopic methods were applied to investigate latent Colletotrichum spp. infection in strawberry plants, but both methods require expensive and specialized laboratory equipment (Krátká et al. 2002; Parikka and Lemmetty 2004; Sreenivasaprasad et al. 1996). By contrast, the LAMP assay is easier to perform and is more time efficient, and its products can be observed by the color change of a suitable indicator (Krátká et al. 2002; Notomi et al. 2000). Fortunately, a LAMP assay for the early detection of $C$. gloeosporioides in strawberry plants was developed here, and this method is feasible for diagnosis in the field. Additionally, the LAMP assay is also suitable for the detection of QoI-resistant C. gloeosporioides.

Primer set S0 was designed for the detection of $C$. gloeosporioides in strawberry plants, which also was used for detecting the G143A mutation. The optimal temperature of the LAMP assay for C. gloeosporioides detection was determined to be $65^{\circ} \mathrm{C}$. C. atramentarium, C. capsici, C. truncatum, and C. gloeosporioides are members of

Table 2. Positive detection of Colletotrichum gloeosporioides in strawberry plants by loop-mediated isothermal amplification (LAMP) and tissue isolation

\begin{tabular}{|c|c|c|c|c|c|c|c|c|}
\hline \multirow[b]{2}{*}{ Isolates } & \multicolumn{2}{|c|}{ Shortened stem } & \multicolumn{2}{|c|}{ Stalk } & \multicolumn{2}{|c|}{ Petiole } & \multicolumn{2}{|r|}{ Leaf } \\
\hline & LAMP & Tissue isolation & LAMP & Tissue isolation & LAMP & Tissue isolation & LAMP & Tissue isolation \\
\hline JD17-1 & + & + & + & + & + & + & - & - \\
\hline JD17-2 & + & + & + & + & + & + & - & - \\
\hline JD17-3 & + & + & + & + & + & + & - & - \\
\hline JD17-4 & + & + & + & + & + & + & - & - \\
\hline JD17-5 & - & - & - & - & - & - & - & - \\
\hline JD17-6 & + & + & + & + & + & + & - & - \\
\hline JD17-7 & + & + & + & + & + & + & - & - \\
\hline JD17-8 & + & + & + & + & + & + & - & - \\
\hline JD17-9 & + & + & + & + & + & + & - & - \\
\hline JD17-10 & + & + & + & + & + & + & - & - \\
\hline JD17-11 & + & + & + & + & + & + & - & - \\
\hline JD17-12 & + & + & + & + & + & + & - & - \\
\hline JD17-13 & + & + & + & + & + & + & - & - \\
\hline JD17-14 & + & + & + & + & + & + & - & - \\
\hline JD17-15 & + & + & + & + & + & + & - & - \\
\hline JD17-16 & + & + & + & + & + & + & - & - \\
\hline JD17-17 & + & + & + & + & + & + & - & - \\
\hline JD17-18 & + & + & + & + & + & + & - & - \\
\hline JD17-19 & + & + & + & + & + & + & - & - \\
\hline JD17-20 & + & + & + & + & + & + & - & - \\
\hline Positive (\%) & 95 & 95 & 95 & 95 & 95 & 95 & 0 & 0 \\
\hline
\end{tabular}


Colletotrichum, and B. cinerea is a typical strawberry pathogen. The genomic DNA of the abovementioned pathogenic fungi were negative to S0, indicating that primer set S0 could distinguish C. gloeosporioides from other Colletotrichum spp. As previously reported (Duan et al. 2016; Hu et al. 2017), the LAMP method was more suitable than PCR for detection of pathogen because of its higher sensitivity, and in the present study, the LAMP assay could detect as little as $10 \times 10^{-4} \mathrm{ng}$ of DNA on ethidium bromide-stained agarose gels and $10 \times 10^{-3}$ ng of DNA under sunlight for HNB color change observed by the naked eye.

The resistance of $C$. gloeosporioides to QoI fungicides has become a severe problem (Avilaadame et al. 2003; Ishii et al. 2007; Wong et al. 2007; Young et al. 2010); in the present study, we detected a high resistance ratio of $71.0 \%$ in strawberry populations of Zhejiang Province. Sequencing revealed that the high resistance resulted from a point mutation at codon $143($ GGT $\rightarrow$ GCT) in the $c y t b$ gene of $C$. gloeosporioides. MIC, the traditional method for the detection of fungicide resistance, requires long detection cycles of a week or even longer. Considering the applicability for the detection of resistance outside the laboratory, here we developed a LAMP assay based on the G143A mutation. Primer set S4 was selected for LAMP assay, and only C. gloeosporioides G143A mutation produced a positive reaction with color changes in HNB and ladder-like bands on the agarose gel. The LAMP assay for the detection of $C$. gloeosporioides with G143A was accomplished under $62^{\circ} \mathrm{C}$ for $50 \mathrm{~min}$, and the results of detection of resistant strain ratios by the LAMP assay was consistent with detection by MIC. Therefore, the LAMP assay could determine accurately the high resistance frequency of $C$. gloeosporioides to QoI fungicides in a short time.

LFDs are used for the detection of pathogens, particularly the detection of pathogenic proteins by the corresponding antibodies or the detection of labels incorporated into LAMP products (Niu et al. 2012; Thornton et al. 2004; Tomlinson et al. 2010). Both methods require specially labeled LFDs, adding to the cost and time. Here, LFDs are only a tool for DNA extraction, saving the cost and time of preparing pathogen-specific antibodies. Genomic DNA from the shortened stem stalk, petiole, and leaf tissues of strawberry plants was extracted within 2 min by using LFDs and was subsequently tested by the LAMP assay. Strawberry plant DNA LAMP had good accuracy. Strawberry plant tissue infected with $C$. gloeosporioides was consistently detected by LAMP and tissue separation, with the same results. The entire LAMP assay was completed within $1 \mathrm{~h}$ without complex genomic DNA extraction and thermal-cycling equipment, increasing the feasibility of using LAMP for the detection of pathogenic fungi.

The diagnosis of strawberry anthracnose and its resistance is significant for farmers. For increasing the yield of strawberry seedlings and shortening production cycle times, the breeding of strawberry plants depends on multiplying from old plants, increasing the risk of plant disease. An appropriate fungicide to control strawberry anthracnose and slow down the occurrence of resistance is urgently needed at the early stage of strawberry development. The LAMP assay developed in this study provides a rapid, sensitive, and specific method for monitoring C. gloeosporioides and its QoI resistance and then guiding the effective use of fungicides, especially at an early stage of strawberry anthracnose.

\section{Literature Cited}

Avila-Adame, C., Olaya, G., and Köller, W. 2003. Characterization of Colletotrichum graminicola isolates resistant to strobilurin-related QoI fungicides. Plant Dis. 87: 1426-1432.

Cannon, P. F., Buddie, A. G. B., and Paul, D. 2008. The typification of Colletotrichum gloeosporioides. Mycotaxon 104:189-204.

Cannon, P. F., Damm, U., Johnston, P. R., and Weir, B. S. 2012. Colletotrichum-Current status and future directions. Stud. Mycol. 73: 181-213.

Damm, U., Cannon, P. F., Woudenberg, J. H., and Crous, P. W. 2012a. The Colletotrichum acutatum species complex. Stud. Mycol. 73:37-113.

Damm, U., Cannon, P. F., Woudenberg, J. H. C., Johnston, P. R., Weir, B. S., Tan, Y. P., Shivas, R. G., and Crous, P. W. 2012b. The Colletotrichum boninense species complex. Stud. Mycol. 73:1-36.
Dean, R., Kan, J. A. L. V., Pretorius, Z. A., Hammond-Kosack, K. E., Pietro, A. D., Spanu, P. D., Rudd, J. J., Dickman, M., Kahmann, R., and Ellis, J. 2012. The Top 10 fungal pathogens in molecular plant pathology. Mol. Plant Pathol. 13:804.

de los Santos García de Paredes, B., and Romero Munoz, F. 2002. Influence of anthracnose epiphytotic development on strawberry fruit production in Huelva (southwestern Spain). Acta Hortic. 567:623-626.

Denoyes, B., and Baudry, A. 1995. Species identification and pathogenicity study of French Colletotrichum strains isolated from strawberry using morphological and cultural characteristics. Phytopathology 85:53-57.

Dhingra, O. D., and Asmus, G. L. 1983. An efficient method of detecting Cercospora canescens in bean seeds. Trans. Br. Mycol. Soc. 81:425-426.

Dolores, F. O. O., Torés, J. A., Antonio, D. V., and Alejandro, P. G. 2010. Field resistance to QoI fungicides in Podosphaera fusca is not supported by typical mutations in the mitochondrial cytochrome $b$ gene. Pest Manag. Sci. 64:694-702.

Duan, Y., Yang, Y., Li, T., Zhao, D., Cao, J., Shi, Y., Wang, J., and Zhou, M. 2016. Development of a rapid and high-throughput molecular method for detecting the F200Y mutant genotype in benzimidazole-resistant isolates of Fusarium asiaticum. Pest Manag. Sci. 72:2128-2135.

Duan, Y. B., Ge, C. Y., Zhang, X. K., Wang, J. X., and Zhou, M. G. 2014 Development and evaluation of a novel and rapid detection assay for Botrytis cinerea based on loop-mediated isothermal amplification. PLoS One 9: e111094.

Fernández-Ortuño, D., Pérez-García, A., López-Ruiz, F., Romero, D., Vicente, A. D., and Torés, J. A. 2006. Occurrence and distribution of resistance to QoI fungicides in populations of Podosphaera fusca in south central Spain. Eur. J. Plant Pathol. 115:215-222.

Forcelini, B. B., Rebello, C. S., Wang, N. Y., and Peres, N. 2018. Fitness, competitive ability, and mutation stability of isolates of Colletotrichum acutatum from strawberry resistant to QoI fungicides. Phytopathology 108: 462-468.

Fraaije, B. A., Cools, H. J., Fountaine, J., Lovell, D. J., Motteram, J., West, J. S., and Lucas, J. A. 2005. Role of ascospores in further spread of QoI-resistant cytochrome $b$ alleles (G143A) in field populations of Mycosphaerella graminicola. Phytopathology 95:933-941.

Freeman, S., and Katan, T. 1997. Identification of Colletotrichum species responsible for anthracnose and root necrosis of strawberry in Israel. Phytopathology 87:516-521.

Freeman, S., Nizani, Y., Dotan, S., Even, S., and Sando, T. 1997. Control of Colletotrichum acutatum in strawberry under laboratory, greenhouse, and field conditions. Plant Dis. 81:749-752.

Genet, J. L., Jaworska, G., and Deparis, F. 2006. Effect of dose rate and mixtures of fungicides on selection for QoI resistance in populations of Plasmopara viticola. Pest Manag. Sci. 62:188-194.

Giblin, F. R., Coates, L. M., and Irwin, J. A. G. 2010. Pathogenic diversity of avocado and mango isolates of Colletotrichum gloeosporioides causing anthracnose and pepper spot in Australia. Australas. Plant Pathol. 39:50-62.

Gunnell, P. S., and Gubler, W. D. 1992. Taxonomy and morphology of Colletotrichum species pathogenic to strawberry. Mycologia 84:157-165.

Han, Y. C., Zeng, X. G., Xiang, F. Y., Ren, L., Chen, F. Y., and Gu, Y. C. 2015 Distribution and characteristics of Colletotrichum spp. associated with anthracnose of strawberry in Hubei, China. Plant Dis. 100:996-1006.

Hu, X. R., Dai, D. J., Wang, H. D., and Zhang, C. Q. 2017. Rapid on-site evaluation of the development of resistance to quinone outside inhibitors in Botrytis cinerea. Sci. Rep. 7:13861.

Ishii, H., Yano, K., Date, H., Furata, A., Sagehashi, Y., and Yamaguchi, T. 2007. Molecular characterization and diagnosis of QoI resistance in cucumber and eggplant fungal pathogens. Phytopathology 97:1458-1466.

Köller, W., Parker, D. M., Turechek, W. W., Avila-Adame, C., and Cronshaw, K 2004. A two-phase resistance response of Venturia inaequalis populations to the QoI fungicides kresoxim-methyl and trifloxystrobin. Plant Dis. 88: 537-544.

Krátká, J., Kudlíková, I., Pekárovákyněrová, B., Slováček, J., and Zemánková, M. 2002. Utilisation of immunochemical methods for detection of Colletotrichum spp. in strawberry. PLoS One 5:e11796.

Mertely, J. C., and Legard, D. E. 2004. Detection, isolation, and pathogenicity of Colletotrichum spp. from strawberry petioles. Monatsh. Chem. 139:1457-1461.

Niu, J. H., Jian, H., Guo, Q. X., Chen, C. L., Wang, X. Y., Liu, Q., and Guo, Y. D. 2012. Evaluation of loop-mediated isothermal amplification (LAMP) assays based on 5S rDNA-IGS2 regions for detecting Meloidogyne enterolobii. Plant Pathol. 61:809-819.

Notomi, T., Okayama, H., Masubuchi, H., Yonekawa, T., Watanabe, K., Amino, N., and Hase, T. 2000. Loop-mediated isothermal amplification of DNA Nucleic Acids Res. 28:63e

Parikka, P., and Lemmetty, A. 2004. Tracing latent infection of Colletotrichum acutatum on strawberry by PCR. Eur. J. Plant Pathol. 110:393-398.

Romero, J., Agustí-Brisach, C., Santa Barbara, A., Cherifi, F., Oliveira, R., Roca, L. F., Moral, J., and Trapero, A. 2018. Detection of latent infections caused by Colletotrichum sp. in olive fruit. J. Appl. Microbiol. 124:209-219.

Shirata, A. 1993. Appearance of the lesion of anthracnose on the mulberry leaves by irradiation with ultraviolet light. Ann. Phytopathol. Soc. Jpn. 59:259-262. 
Siah, A., Elbekali, A. Y., Ramdani, A., Reignault, P., Torriani, S. F. F., Brunner, P. C., and Halama, P. 2014. QoI resistance and mitochondrial genetic structure of Zymoseptoria tritici in Morocco. Plant Dis. 98:1138-1144.

Sreenivasaprasad, S., Mills, P. R., Meehan, B. M., and Brown, A. E. 1996. Phylogeny and systematics of 18 Colletotrichum species based on ribosomal DNA spacer sequences. Genome 39:499-512.

Sreenivasaprasad, S., and Talhinhas, P. 2005. Genotypic and phenotypic diversity in Colletotrichum acutatum, a cosmopolitan pathogen causing anthracnose on a wide range of hosts. Mol. Plant Pathol. 6:361-378.

Sutton, B. C., Bailey, J. A., and Jeger, M. J. 1992. The genus Glomerella and its anamorph Colletotrichum. Pages 1-26 in: Colletotrichum: Biology, Pathology and Control. CAB International, Wallingford, U.K.

Thornton, C. R., Groenhof, A. C., Forrest, R., and Lamotte, R. 2004. A one-step, immunochromatographic lateral flow device specific to Rhizoctonia solani and certain related species, and its use to detect and quantify $R$. solani in soil. Phytopathology 94:280-288.

Tomlinson, J. A., Dickinson, M. J., and Boonham, N. 2010. Rapid detection of Phytophthora ramorum and P. kernoviae by two-minute DNA extraction followed by isothermal amplification and amplicon detection by generic lateral flow device. Phytopathology 100:143-149.

Torriani, S. F., Goodwin, S. B., Kema, G. H., Pangilinan, J. L., and McDonald, B. A. 2008. Intraspecific comparison and annotation of two complete mitochondrial genome sequences from the plant pathogenic fungus Mycosphaerella graminicola. Fungal Genet. Biol. 45:628-637.

Turechek, W. W., Peres, N. A., and Werner, N. A. 2006. Pre- and post-infection activity of pyraclostrobin for control of anthracnose fruit rot of strawberry caused by Colletotrichum acutatum. Plant Dis. 90:862-868.
Valeria, G., Simona, P., Helge, S., Angelo, G., and Ulrich, G. 2010. Cytochrome $b$ gene structure and consequences for resistance to Qo inhibitor fungicides in plant pathogens. Pest Manag. Sci. 62:465-472.

Wang, J. G., Zhao, S. F., Xu, Y. H., Hu, X. X., Ke, H. Y., and Hong, Z. H 2014. Field effect test and security analysis of pyraclostrobin on strawberry, balsam pear and cucumber anthracnose. Chinese Horticulture Abstracts. http://en.cnki.com.cn/Article_en/CJFDTotal-YUWZ201405024. htm

Weir, B., Johnston, P., and Damm, U. 2012. The Colletotrichum gloeosporioides species complex. Stud. Mycol. 73:115-180.

Wong, F. P., Midland, S. L., and Ka, D. L. C. 2007. Occurrence and distribution of QoI-resistant isolates of Colletotrichum cereale from annual bluegrass in California. Plant Dis. 91:1536-1546.

Xie, L., Zhang, J. Z., Wan, Y., Hu, D. W. 2010. Identification of Colletotrichum spp. isolated from strawberry in Zhejiang Province and Shanghai City, China. J. Zhejiang Univ. Sci. B 11:61-70.

Yamazaki, S., Ohno, Y., and Ishikawa, S. 1995. Diagnostic method of latent infection of cyclamen anthracnose. Ann. Phytopathol. Soc. Jpn. 61(6).

Young, J. R., Tomaso-Peterson, M., Tredway, L. P., and Cerda, K. D. L. 2010 Occurrence and molecular identification of azoxystrobin-resistant Colletotrichum cereale isolates from golf course putting greens in the southern United States. Plant Dis. 94:751-757.

Zhang, C. Q., Liu, Y. H., and Zhu, G. N. 2010. Detection and characterization of benzimidazole resistance of Botrytis cinerea in greenhouse vegetables. Eur. J. Plant Pathol. 126:509-515.

Zhao, M. Z., Wang, J., Wang, Z. W., Qian, Y. M., and Wu, W. M. 2012. Strawberry production and trade in the world. Fruit Grow Friend. 6:38 